\title{
CREATING 3D MODELS WITH 3D PRINTING PROCESS
}

\author{
Filip Popovski ${ }^{1}$, Svetlana Mijakovska ${ }^{1}$, \\ Hristina Dimova Popovska ${ }^{2}$ and Gorica Popovska Nalevska ${ }^{3}$ \\ ${ }^{1}$ Faculty of Technical Sciences, SS Kliment Ohridski, Makedonska Falanga 34, \\ 7000 Bitola, R. Macedonia \\ ${ }^{2}$ SABA High School, Istarska 33, 1000 Skopje, R. Macedonia \\ ${ }^{3}$ International Slavic University Gavrilo Romanovic Derzavin, 7000 Bitola, \\ R. Macedonia
}

\begin{abstract}
This scientific paper will cover the process of creating two 3D objects, accompanied by a brief history of $3 D$ printing technology, designing the model in CAD software, saving in appropriate format supported by the $3 D$ printer, features of technology and the printer, materials from which the object can be made and examples where the products created by the $3 D$ printing process can be applied. The printing of models was made by the studio "Xtrude Design \& 3D Print" in Skopje. Two 3D models have been printed. A creative model of intertwined 4 triangles in STL file format has been made, which will be transferred and printed with PLA material. The model with the heart on the stand is printed with popular FDM process also with PLA material which is biodegradable and environmentally friendly. Both models are printed on Anet A8 3D printer. Different printing times, layer thicknesses and cost price of producion we have in our research.
\end{abstract}

\section{KEYWORDS}

Modeling, 3D Printing, Computer design, 3D Software, Materials.

\section{INTRODUCTION}

3D digitization and printing of buildings, vehicles, toys is extensively used in the fields of Architecture, Engineering and Construction (AEC). This has led to the development of multiple robotic platforms for the digitization of buildings and vehicles in recent years [1]. Nevertheless, the point models that are generated are almost exclusively used to evaluate the geometric features of them [2][3][4][5]. Graphic systems are getting better, faster and cheaper at a bewildering rate and many new techniques are emerging each year from researchers and practitioners around the world, but the underlying principles and approaches constitute a stable and coherent body of knowledge [6]. 3D printing is a technology where a three-dimensional object is created by placing successive layers of material on top of each other. These layers are micrometer thick, usually 50 to $100 \mu \mathrm{m}$. 3D printing is achieved with additive process, where successive layers of material are placed in different shapes according to the shape should be made. This process is also known as additive production and refers to technologies that create objects through sequential layering where layers are added on top of each other [7].

In contrast to the additive production there is a subtractive production that starts with a given material and removes the excess material until the desired shape remains. 
There are several methods of 3D printing [8]. The most common method is Fused Deposition Modeling (FDM). This method uses a nozzle head to extrude molten material, usually plastic, layer by layer on the platform according to the 3D data submitted to the printer. Another 3D printing process, such as stereolithography (SLA), uses a liquid photosensitive polymer that solidifies when exposed to UV light. Used for complex designs. Selective laser sintering (SLS) combines powdered materials with bonding spray. Today, these methods are even more expensive and more specialized than FDM. 3D printing technology can revolutionize and reshape the world. Advances in 3D printing technology can significantly change and improve the way that products are produced worldwide.

\section{Creating 3D Models}

Designing in 3D can sometimes be a very simple and advanced process, but even the simplest design can be a big challenge. When we speak for 3D printing, the easier way that we make the model is better. Although the 3D model that looks great on the screen it does not make it a perfect form for 3D printing. Some details may be lost during the 3D printing process or some elements may be too thin to print or the pattern may not be strong enough. Some things can be easily fixed or fixed during the design phase when use automatic checking and repair tools, while other problems can't be solved until the model is actually printed [11].

\subsection{Characteristics of the Models}

- The most common question about 3D printing is whether the model is closed or not. All edges should be connected to each other. There should be no edges or vertices that do not create a closed surface, as there will be no thickness for 3D printing.

- Another common mistake that can be made when exporting files is that they will not have volume. Game models are optimized for rendering, not printing, even if it means a little illusion with the geometry. Hair, for example, is sometimes created on simple textured shapes without volume. Such items may not be printable. To prepare a model for 3D printing, the surfaces must first be given volume [10].

- Will the model be stable? If the model for example is a figure running where one foot will be on the ground and the other in the air. This model will not stand upright and will fall. Maybe it's a good idea to add a stand. Large objects with thin bases should be not accepted.

- The best way for smoothing the object is to a certain extend. Files over the maximum size of $50 \mathrm{mb}$ are problematic when using optimization tools. One way to reduce the file size is to reduce the number of polygons. Most 3D applications contain that tool. If it does, Blender tool can always be used.

\subsection{Software for $3 D$ printing}

In Table 1 will be presented all file formats that support 3D printing with all their characteristics. There are a lot of software tools that can be used for 3D printing [9].

Table 1. File formats that support 3d printing

\begin{tabular}{|l|l|l|l|}
\hline Format & 3D geometry & Color & Texture \\
\hline STL & $\checkmark$ & $\boldsymbol{X}$ & $\boldsymbol{X}$ \\
\hline OBJ (Wavefront) & $\checkmark$ & $\checkmark$ & $\checkmark$ \\
\hline SKP (Sketchup) & $\checkmark$ & $\checkmark$ & $\checkmark$ \\
\hline OFF & $\checkmark$ & $\boldsymbol{X}$ & $\boldsymbol{X}$ \\
\hline PLY (Standford) & $\checkmark$ & $\checkmark$ & $\boldsymbol{X}$ \\
\hline
\end{tabular}


International Journal of Computer Science \& Information Technology (IJCSIT) Vol 13, No 6, December 2021

\begin{tabular}{|l|l|l|l|}
\hline KMZ (Google Earth) & $\checkmark$ & $\checkmark$ & $\checkmark$ \\
\hline 3DS (3D Studio) & $\checkmark$ & $\checkmark$ & $\checkmark$ \\
\hline AC3D & $\checkmark$ & $\checkmark$ & $\checkmark$ \\
\hline DAE (Collada) & $\checkmark$ & $\checkmark$ & $\checkmark$ \\
\hline MD2/MD3 & $\checkmark$ & $x$ & $x$ \\
\hline Q3O (Quick3D) & $\checkmark$ & $\checkmark$ & $\checkmark$ \\
\hline COB (TrueSpace) & $\checkmark$ & $\checkmark$ & $x$ \\
\hline DXF (AutoCAD) & $\checkmark$ & $\checkmark$ & $x$ \\
\hline LWO (LightWave) & $\checkmark$ & $\checkmark$ & $\checkmark$ \\
\hline VRML & $\checkmark$ & $\checkmark$ & $\checkmark$ \\
\hline SCAD & $\checkmark$ & $x$ & $x$ \\
\hline ZIP, RAR, TGZ & $\checkmark$ & $\checkmark$ & $\checkmark$ \\
\hline
\end{tabular}

In Table 2 will be presented all software for 3D modelling that support 3D printing.

Table 2. Software for 3D modelling

\begin{tabular}{|l|l|}
\hline 3D Studio Max & MicroStation \\
\hline 3D Studio Viz & Mimics \\
\hline Alias & Pro/ENGINEER \\
\hline AutoCad & Raindrop Geomagic \\
\hline Bentley Triforma & RapidForm \\
\hline Blender & RasMol \\
\hline CATIA & Revit \\
\hline COSMOS & Meshmixer \\
\hline Form Z & SketchUp \\
\hline Inventor & Solid Edge \\
\hline LightWave 3D & Solidworks \\
\hline Magics e-RP & UGS NX \\
\hline Maya & Vectorworks \\
\hline
\end{tabular}

\subsection{Creating 3D model in 3D Studio Max}

Autodesk 3d Studio Max is a professional 3D program. Our model starts with applying one of the primitives and using tools like bevel and extrude. This is a basic method, by which modeling begins using only cubes, spheres, cones, cylinders and other predefined objects from the list of standard primitives. Boolean operations can also be performed, including subtraction, reduction and connection.

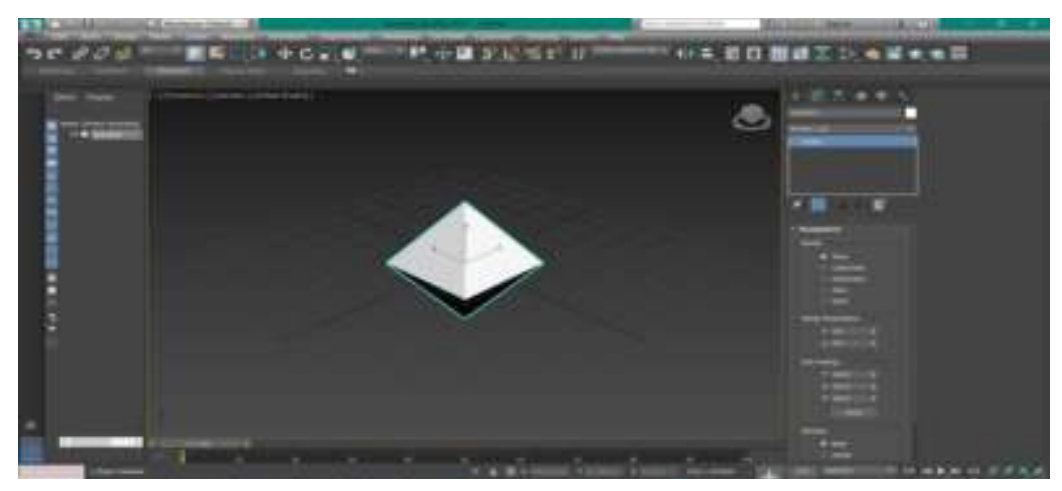

Figure 1. Creating shape Hedra with radius $25.4 \mathrm{~mm}$ 
International Journal of Computer Science \& Information Technology (IJCSIT) Vol 13, No 6, December 2021

From the list of modifiers we add Edit Poly, select Edge then Split. From the Polygon section, we select all the polygons, add a $2.5 \mathrm{~mm}$ Inset and delete the selected polygons.

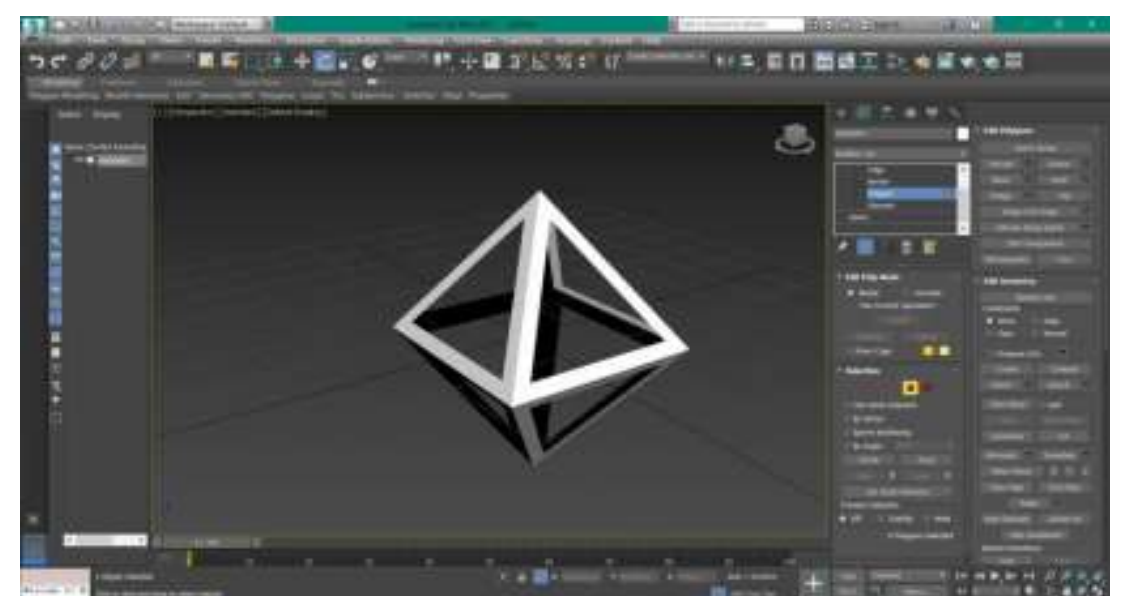

Figure 2. Creating visible model for 3D printing

Then, from the list of modifiers we add Push modifier, with a value for push value of $14.6575 \mathrm{~mm}$ and we get a polygon as in picture 3 .

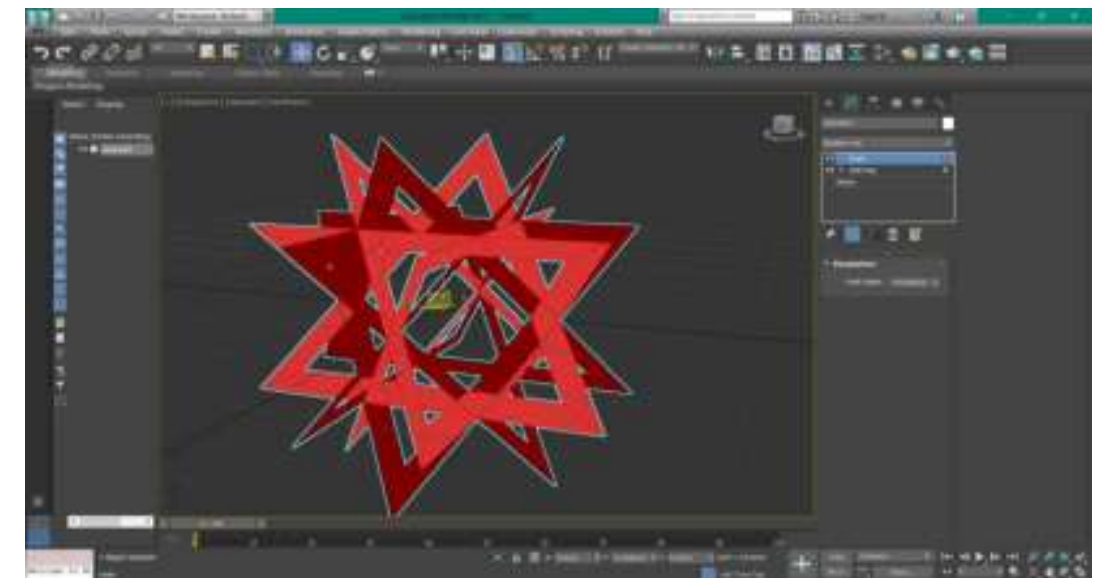

Figure 3. Modification of 3D model

Once we get the shape of the desired model, we add thickness. For this purpose we add a Shell modifier with an outer amount of $2.6 \mathrm{~mm}$ which adds volume to the model. 


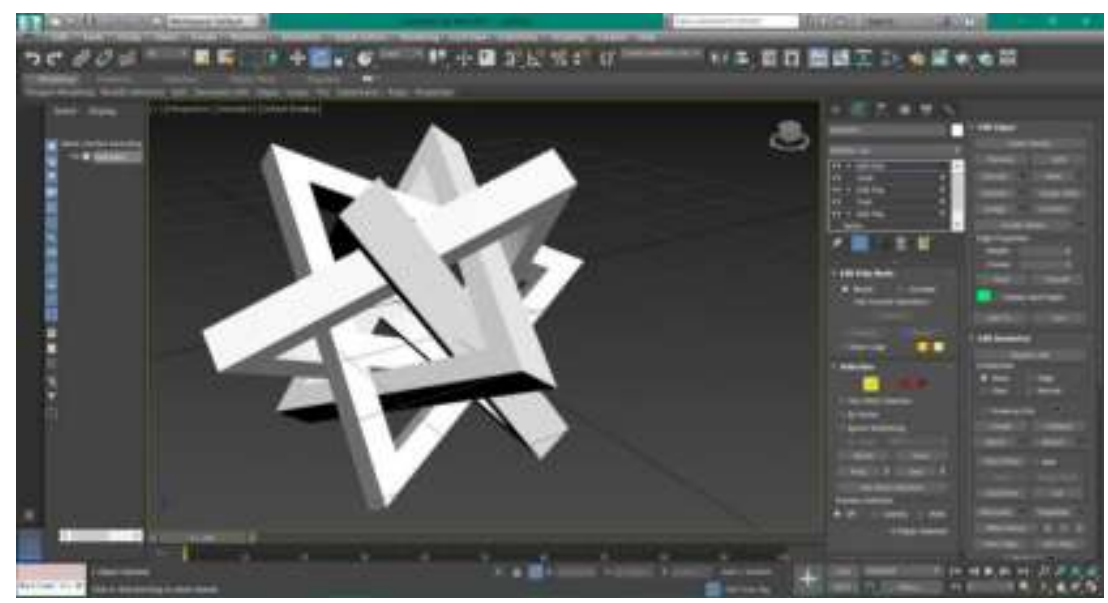

Figure 4. 3D model ready for 3D printing

\section{Printing Process}

The FDM process will be used to print the model. FDM printers use two types of materials: modeling material, which makes up the whole object and backing material, which acts as a supporting skeleton for the object that will be printed [16]. During printing, these materials are in the form of plastic threads that unwind from the coil. The nozzle melts the filaments and extrudes them onto the substrate, sometimes called the printing platform. Both the nozzle and the base are controlled by a computer that translates the dimensions of the object into the $\mathrm{X}, \mathrm{Y}$ and $\mathrm{Z}$ coordinates for the nozzle and base to follow during printing. Typically, the head moves in layers, moving in two dimensions to print a horizontal plane, before going up to start a new piece. The speed of the extruder head can also be controlled to stop and start releasing the material. The printing time depends on the size of the object being produced. Small objects print quickly, while for printing larger objects, more geometrically complex objects, the procedure takes longer. Compared to other 3D printing methods, such as stereolithography (SLA) or selective laser sintering (SLS), FDM is a rather slow process.

\subsection{Printing Materials}

There is no technology that can print on any material. Some of them support a wide range of materials, while others can only work with one specific material [14]. Table 3 lists the most popular materials used for 3D printing.

Table 3. Separation of materials for 3D printing

\begin{tabular}{|l|l|l|l|}
\hline \multicolumn{4}{|c|}{ MATERIALS } \\
\hline PLASTIC & METAL & RESIN & OTHER \\
\hline Polyamide (PA) & Bronze & Transparent & Wax \\
\hline Polylactide (PLA) & Aluminum & Non-Transparent & Ceramics \\
\hline ABS & Gold, Silver & Flexible & Wood \\
\cline { 1 - 2 } $\begin{array}{l}\text { Thermoplastic } \\
\text { Polyurethane (TPU) }\end{array}$ & Titanium & & \\
\cline { 1 - 2 } PET & Iron & & \\
\cline { 1 - 2 } PETG, PC, TPE & \multicolumn{2}{|l}{} & \\
\cline { 1 - 2 } & &
\end{tabular}




\subsection{Printing Process}

The model was printed on Anet A8 3D printer. The printer is of satisfactory quality for the price. Before printing, it needs to be calibrated and then plugged in. It heats up according to the material to be used for printing. Then adjust the material for printing. The object is selected from the memory card. When the process starts, the plates move depending on the X, Y, Z axes. When the model is ready, it appears on the display $100 \%$ [13].

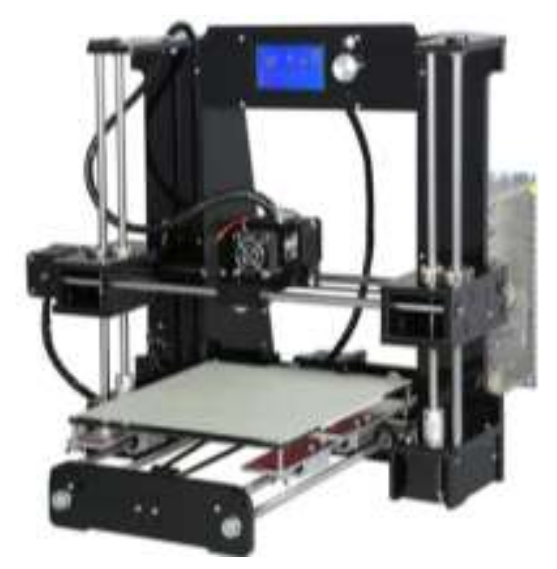

Figure 5. 3D Printing Machine Anet A8

Table 4. Important technical specifications of printer

\begin{tabular}{|l|l|}
\hline Filament diameter & $1.75 \mathrm{~mm}$ \\
\hline Printing area & $220 \times 220 \times 240 \mathrm{~mm}$ \\
\hline Printing time & $100 \mathrm{~mm} / \mathrm{s}$ \\
\hline Nozzle diameter & $0.4 \mathrm{~mm}$ \\
\hline Layer thickness & $0.10 .3 \mathrm{~mm}$ \\
\hline Temperature & $10-30^{\circ} \mathrm{C}$ \\
\hline Humidity & $20-50 \%$ \\
\hline Materials & ABS, PLA, TPU, Carbon Fiber \\
\hline Supported file formats & G-code, OBJ, STL \\
\hline Price & $200 €$ \\
\hline
\end{tabular}

In the printing process of this model, stands are needed to print in good condition and they are automatically generated by the program for the preparation of the 3D printing object. Printing time is $100 \mathrm{~mm} / \mathrm{s}$ and model to complete need around $200 \mathrm{~min}$. 


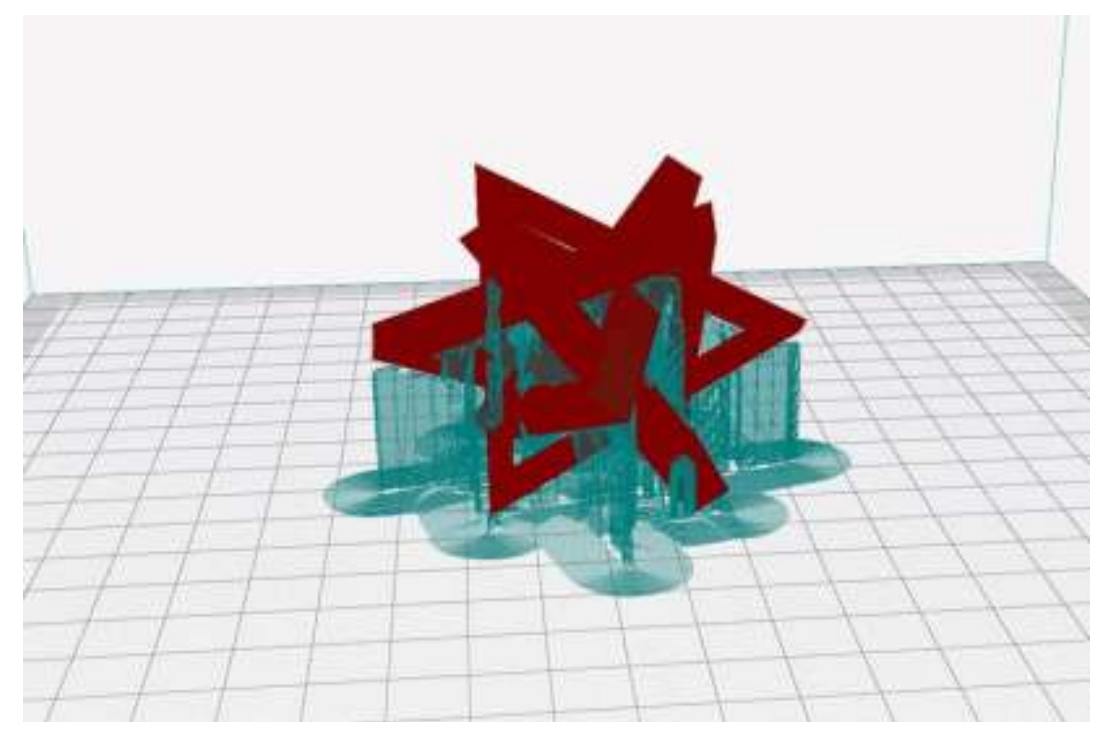

Figure 6. Setting up a stand for proper printing of the object

When printing is finished, the excess material is removed with pliers, sandpaper, scalpel, etc. The model is printed with polylactide, which is a biodegradable and bioactive thermoplastic aliphatic polyester obtained from renewable sources, such as cornstarch, cassava, nettle or sugar cane.

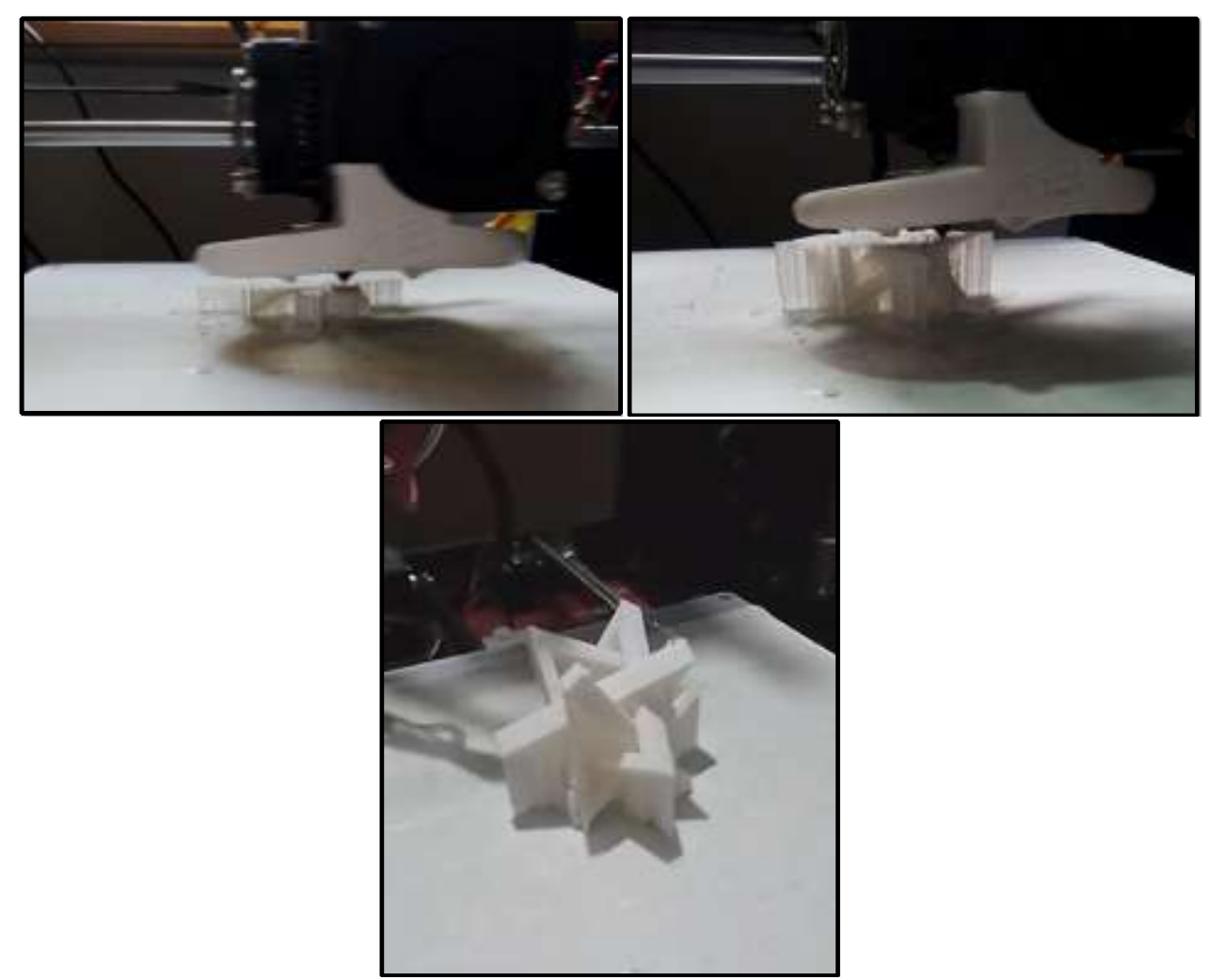

Figure 7. Printing of the model in all phases 


\subsection{D Models}

Two 3D models have been printed. One is in the shape of stars and the other is in the shape of a heart. Both models have their own characteristics that we will examine and compare in this scientific paper.

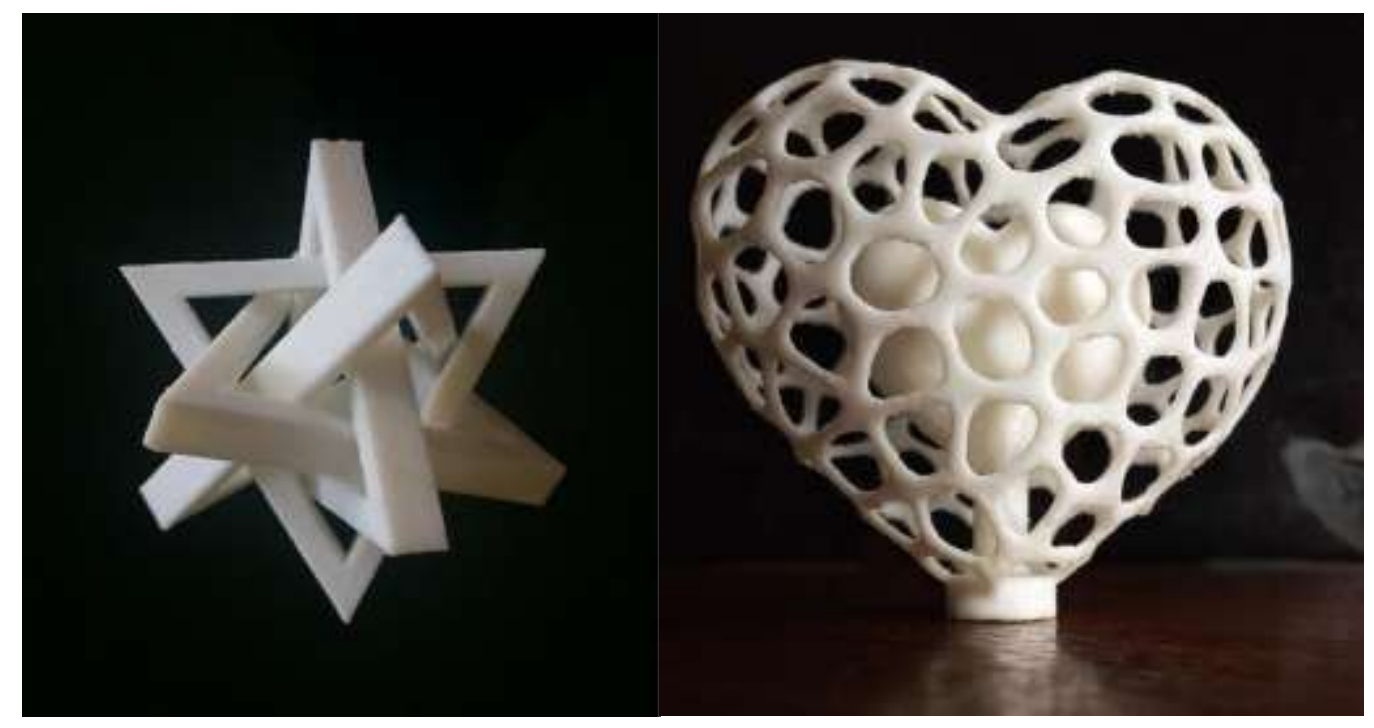

Figure 8. 3D Star model and 3D heart model

\section{Results AND ANAlysis}

Two models have been printed in FDM Technology. The printing of the model of heart on a standwith dimensions of $6.6 \times 5.8 \times 2.9 \mathrm{~cm}$, lasted 5 hours and the model with the triangles with dimensions of $6.6 \times 5.1 \times 6.6$ lasted 3 hours and 20 min. Both models have a melting point of 130 $-180^{\circ} \mathrm{C}$. Both models are printed with a layer thickness of 0.1 to $0.2 \mathrm{~mm}$.

Table 5. Comparing performance and times of 3D Printing

\begin{tabular}{|l|l|l|}
\hline & 3D Star Model & 3D Heart model \\
\hline Dimensions $(\mathrm{cm})$ & $6.6 \times 5.1 \times 6.6$ & $6.6 \times 5.8 \times 2.9$ \\
\hline Production Time (minutes) & 200 & 300 \\
\hline Melting Point $\left({ }^{\circ} \mathrm{C}\right)$ & $130-180$ & $130-180$ \\
\hline Layer Thickness $(\mathrm{mm})$ & $0.1-0.2$ & $0.1-0.2$ \\
\hline 3D Printing Technology & $\begin{array}{l}\text { FDM (Fused Deposition } \\
\text { Modeling) }\end{array}$ & $\begin{array}{l}\text { FDM (Fused Deposition } \\
\text { Modeling) }\end{array}$ \\
\hline Materials & Polylactide (PLA) & Polylactide (PLA) \\
\hline
\end{tabular}

\section{Conclusions}

This new technology in the last decade has allowed many designers and engineers to access realistic 3D models. In recent years, this technology has become increasingly available for personalized use at home and for business. Reasons for this are easily available printers with affordable prices depending on the quality.

This is a new technology that is becoming more and more relevant, it has a number of applications starting from specialized models and parts for automotive, construction, space, 
chemical industry, by printing a growing range of materials such as iron, alloys, copper to printing toys, useful tools, fashion industry with plastic materials, resins, ceramics and others [15].

Two 3D models have been printed. The model with the heart on the stand is made with dimensions of $6.6 \times 5.8 \times 2.9 \mathrm{~cm}$ while the model with the intertwined triangles has dimensions $6.6 \times 5 \times 6.6$. The resolution is the fineness of the models and the thickness of each layer is 0.2 $\mathrm{mm}$. The model was printed in Xtrude Design \& 3D Print studio in Skopje. The most popular FDM printing process is used, with plastic material - polylactide (PLA) which is biodegradable and environmentally friendly, at the same time most suitable for printing such models. [12]. Our comparison proved that the fineness of the CAD model can increase the thickness of the printing layers from 0.1 to 0.2 and will save time and money. At the same time the material is biodegradable and not harmful to the environment. By reducing the printing time we got a better cost.

Everything new is interesting, especially when there is great potential for future application. 3D printing technology is still a new everyday process that is expected to become popular for everyday use, ordering and need, while in industry, design and engineering it is already used and there are great opportunities to improve the application.

\section{REFERENCES}

[1] Adán, A.; Quintana, B.; Prieto, (2019), S.A. Autonomous mobile scanning systems for the digitization of buildings: A review. Remote Sens. 2019, 11, 306, doi:10.3390/rs11030306

[2] Valero, E.; Adan, A.; Huber, D.; Cerrada, C. Detection, (2011), Modeling and Classification of Moldings for Automated Reverse Engineering of Buildings from 3D Data. In Proceedings of the 28th International Symposium on Automation and Robotics in Construction (ISARC), Seoul, Korea, 29 June-2 July 2011; doi:10.22260/ISARC2011/0099.

[3] Quintana, B.; Prieto, S.A.; Adán, A.; Vázquez, A.S. (2016), Semantic Scan Planning for Indoor Structural Elements of Buildings. Adv. Eng. Inform. 2016, 30, 643-659, doi:10.1016/j.aei.2016.08.003.

[4] Macher, H.; Landes, T.; Grussenmeyer, P. (2017), From point clouds to building information models: 3D semi-automatic reconstruction of indoors of existing buildings. Appl. Sci. 2017, 7, 1030, doi:10.3390/app7101030.

[5] Wang, Q.; Kim, M.K. (2019), Applications of 3D point cloud data in the construction industry: A fifteen-year review from 2004 to 2018. Adv. Eng. Inform. 2019, 39, 306-319, doi:10.1016/j.aei.2019.02.007.

[6] Hill F. (2000), Computer Graphics Using Open GL (2nd Edition), Prentice Hall

[7] Kalani H.; Richard H. (2014), 3D Printing for dummies, 1-72

[8] Vipul G.; Pavel N.; Brett P., (2019), An Introduction to 3D printing, 3D Printing in Chemical Sciences: Applications Across Chemistry, 2019, pp. 1-21 doi: 10.1039/9781788015745-00001

[9] Mark F., (2013), Ultimate guide to 3D Printing, Make Magazin winter 2013, pp1-116

[10] Design Guidelines, (2015), Sculpteo, 2015, pp 1-34

[11] Fix your files for 3D printing, (2017), Sculpteo 2017 pp 1-21

[12] 3D Printing Materials Bible, (2016) Sculpteo, 2016 edition, pp 1-40

[13] How 3D Printing Works, (2012), 3D Maker Engineering

[14] R. Holtrup (2015), Design and Construction of a Multi-material 3D DLP Printer, University of Twente, 2015

[15] Forbes Technology Council, (2018), 11 Tech Pros Share Their Favourite Applications Of 3D Printing Technology.

[16] Elizabeth P., (2013), Fused Deposition Modelling: Most Common 3D Printing Method 


\section{Authors}

Prof. Filip Popovski is a Doctor of Technical Sciences in Graphic Engineering at Faculty of Technical Sciences in Bitola, Macedonia. He is interested in computer graphics, visualization, 3d Virtual reality.

Prof. Svetlana Mijakovska is a Doctor of Technical Sciences in Graphic Engineering at Faculty of Technical Sciences in Bitola, Macedonia. She is interested in computer graphics, visualization, $3 \mathrm{~d}$ Virtual reality

Prof. Hristina Dimova Popovska is a Master of Information Sciences at Faculty of Information Sciences in Bitola, Macedonia. She is interested in computer graphics, internet of things etc.

Prof. Gorica Popovska Nalevska is a Doctor of pedagogy at International Slavic University Gavrilo Romanovic Derzavin in Bitola, Macedonia. 